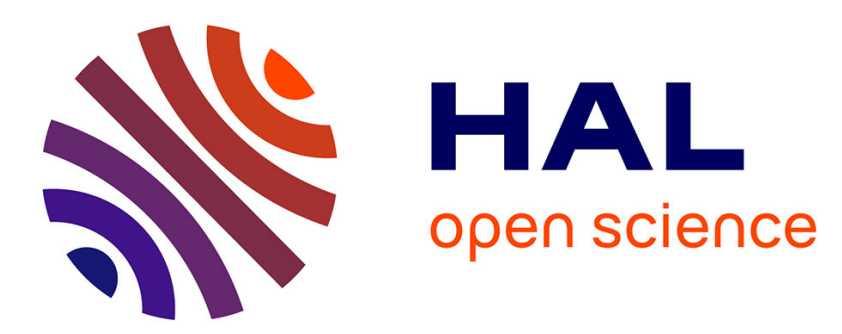

\title{
Reactive compatibilization of polymer blends by $\gamma$-irradiation: Influence of the order of processing steps
}

Rodolphe Sonnier, Valérie Massardier-Nageotte, Laurent Clerc, José-Marie Lopez-Cuesta, Anne Bergeret

\section{- To cite this version:}

Rodolphe Sonnier, Valérie Massardier-Nageotte, Laurent Clerc, José-Marie Lopez-Cuesta, Anne Bergeret. Reactive compatibilization of polymer blends by $\gamma$-irradiation: Influence of the order of processing steps. Journal of Applied Polymer Science, 2010, 115 (3), pp.1710-1717. 10.1002/app.31313 . hal-00458686

\section{HAL Id: hal-00458686 \\ https://hal.science/hal-00458686}

Submitted on 27 May 2021

HAL is a multi-disciplinary open access archive for the deposit and dissemination of scientific research documents, whether they are published or not. The documents may come from teaching and research institutions in France or abroad, or from public or private research centers.
L'archive ouverte pluridisciplinaire HAL, est destinée au dépôt et à la diffusion de documents scientifiques de niveau recherche, publiés ou non, émanant des établissements d'enseignement et de recherche français ou étrangers, des laboratoires publics ou privés. 


\title{
Reactive Compatibilization of Polymer Blends by $\gamma$-Irradiation: Influence of the Order of Processing Steps
}

\author{
Rodolphe Sonnier, ${ }^{1,2}$ Valérie Massardier, ${ }^{2}$ Laurent Clerc, ${ }^{1}$ Jose Marie Lopez-Cuesta, ${ }^{1}$ \\ Anne Bergeret ${ }^{1}$ \\ Centre des Matériaux de Grande Diffusion, Ecole des Mines d'Alès, Alès 30100, France \\ Laboratoire des Matériaux Macromoléculaires, UMR IMP CNRS 5627, Villeurbanne F-69621, France
}

\begin{abstract}
Results concerning $\gamma$-irradiation of polymer blends such as HDPE/ground tire rubber (GTR) and $\mathrm{PP} / \mathrm{HDPE}$ are reported in this article with a special emphasis on the order of processing steps. Irradiation dose varied in the range $0-100 \mathrm{kGy}$. The two first polymers (HDPE and rubber) are preferentially crosslinked under $\gamma$ irradiation while PP undergoes chain scission. Mechanical tests and differential scanning calorimetry (DSC) analysis show that the efficiency of the reactive compatibilization by $\gamma$ irradiation depends greatly on the chronology of $\gamma$-irradiation and injection-molding steps. Electron spin
\end{abstract}

\section{INTRODUCTION}

Ionizing radiations provoke great changes in polymeric structure. The formation of free radicals in materials leads to chain scissions, crosslinking and oxidative degradation. One application of radiations is in the compatibilization of polymer blends, as macroradicals of two polymers combine to form new bondings. Numerous polymer blends were compatibilized by irradiation ( $\gamma$ or electron-beam irradiation) with more or less success: $\mathrm{PE} /$ rubber waste, $\mathrm{PP} / \mathrm{PE}$, $\mathrm{PP} / \mathrm{PA}, \mathrm{PS} / \mathrm{SBR}, \mathrm{PP} / \mathrm{PS}, \mathrm{HDPE} / \mathrm{EVA}^{1-7}$ for example.

The efficiency of radiations depends on polymer structure, which influences strongly the ratio between crosslinking, chain scission and other phenomena. For many rubbers, the presence of $\mathrm{C}=\mathrm{C}$ unsaturations leads to an easy crosslinking of the polymer. In the case of HDPE, with medium or low doses, crosslinking is simplified due to the hydrogen abstraction from the secondary carbon (to form a macroradical) and due to the combination between two macroradicals. ${ }^{8,9}$ Polyethylene undergoes chain scissions at high doses. ${ }^{10}$ On the contrary, the presence of tertiary carbons in PP enhances chain scissions by rearrangement of macroradicals.

Correspondence to: R. Sonnier (rodolphe.sonnier@ema.fr). resonance (ESR) results reveal that numerous radicals remain trapped in the materials after $\gamma$-irradiation even after a long time. Then the effect of irradiation on material properties is different if polymers are melted after irradiation or not. Crosslinking and chain scission are not affected in an equivalent way by the order of processing steps.

Key words: gamma irradiation; compatibilization; polyolefin; thermoplastic processing

Side reactions, like oxidation (especially in air), radical rearrangement or radical transfer from polymer to antidegrading agent, ${ }^{11}$ compete with these phenomena.

Other parameters can modify the efficiency of irradiation, such as the compatibility of polymers, ${ }^{12}$ the atmosphere, ${ }^{13}$ the radiation rate and the total dose. For example, Miguez Suarez et al. ${ }^{10}$ have shown that LDPE undergoes crosslinking reactions at low doses but chain scissions at high doses. Polyfunctional monomer could be added to control the radical reactions, particularly to favor the crosslinking of PP. ${ }^{3,14,15}$

Contrary to chemical reactions using peroxides, irradiation is performed in solid state, at an ambient temperature. Different researchers have demonstrated that many radicals are frozen in materials, especially in crystalline zones. ${ }^{16-18}$ In the case of PP, Rivaton et al. have noticed that these long-life radicals migrate slowly to amorphous-crystalline boundary and could react with oxygen during postirradiation. According to Chen et al., ${ }^{16}$ an oxidation process generally involves different radicals, especially alkyl and peroxy radicals:

$$
\mathrm{P} \rightarrow \mathrm{R}^{*}(\text { alkyl radical })
$$

$$
\mathrm{R}^{*}+\mathrm{O}_{2} \rightarrow \mathrm{ROO}^{*} \text { (peroxy-radicals, faster reactions) }
$$

$\mathrm{ROO}^{*} \rightarrow \mathrm{ROOH}+\mathrm{ROOR}$ (peroxides, slower reaction) 
Thus postirradiation reactions could strongly contribute to the degradation of mechanical properties during storage.

But very few articles concern the influence of the process on mechanical properties of irradiated blends. When the irradiation is carried out before the injection-molding (on pellets), then all frozen radicals could react during the injection. On the contrary, if irradiation is performed on molded pieces, the changes are involved only in amorphous zones and radicals remain trapped in crystallites. Khonakdar et al. $^{8}$ noted that the crystallinity content and melting temperature of irradiated PE only change after a first heating ramp due to reaction of the radicals frozen in crystalline zones.

In this article, we have studied the influence of the processing on the efficiency of gamma irradiation to compatibilize two different blends at low or medium doses (up to $100 \mathrm{kGy}$ ). The first was a PP/ HDPE blend. PP is known to undergo preferentially chain scission and HDPE is crosslinked in presence of radicals. The second blend was studied in the perspective of tires recycling and involves HDPE and ground tire rubber (GTR) which is subjected to crosslink too. In all cases, irradiation was applied on the pellets before injection molding or on the molded parts, which were then tested.

\section{EXPERIMENTAL}

\section{Materials}

The composition of the first blend is $80 \mathrm{wt} \% \mathrm{PP}$ and 20 wt \% HDPE1. Virgin polypropylene is PP108 MF97, a high-impact polypropylene from Sabic Europe (Netherlands) which contains $22 \%$ of ethylene-propylene rubber (EPR). HDPE1 is a very viscous high density polyethylene: Lupolen 7461 from Basell.

The second blend contains $50 \mathrm{wt} \%$ HDPE2 and 50 wt \% GTR. High density polyethylene HDPE2 is a recycled material. Rubber particles mean size is $\sim 400 \mu \mathrm{m}$. Car and truck tires rubber is ground by Granuband (The Netherlands). Some results concerning HDPE2/GTR blends 50/50 are given in Sonnier et al. ${ }^{2}$

\section{Processing}

Blends were compounded using a twin screw Clextral BC 21 extruder $\left(220^{\circ} \mathrm{C}\right.$ and $120 \mathrm{rpm}$ for $\mathrm{PP} / \mathrm{HDPE} 1,180^{\circ} \mathrm{C}$ and $250 \mathrm{rpm}$ for HDPE2/GTR) and then pelletized.

Pellets were then injection-molded before or after irradiation using following injection molding machine to obtain tensile test specimen: 95 tons Sandretto AT press. Injection temperature was $220^{\circ} \mathrm{C}$ for PP/HDPE1 and $170{ }^{\circ} \mathrm{C}$ for HDPE2 and HDPE2/ GTR.

For molded pieces prepared from irradiated pellets, the time between irradiation and injectionmolding was 2 weeks.

\section{Gamma irradiation}

Irradiation was performed by Ionisos SA (France), on the pellets and on molded pieces, using a $2 \times 10^{6}$ $\mathrm{Ci}{ }^{60} \mathrm{Co}$ source, under air atmosphere and at ambient temperature. Irradiation dose was controlled with a precision of $\pm 15 \%$ for minimum dose and $\pm 5 \%$ for maximum dose. Dose rate was $2 \mathrm{kGy} / \mathrm{h}$. Final doses ranged from 0 to $50 \mathrm{kGy}$ for PP/HDPE1 blends and 0 to 100kGy for HDPE2 and HDPE2/GTR.

Irradiated pellets and molded pieces were stored in air at ambient temperature.

$\gamma$-irradiation is a very penetrating radiation, that's why no difference should be expected for different thicknesses of samples $(1 \mathrm{~mm}$ for pellets and $4 \mathrm{~mm}$ for standard specimens).

\section{Electron spin resonance (ESR) measurements}

For PP/HDPE1 blends, electron spin resonance (ESR) spectra were recorded using a Bruker Elexsys e500 X-Band $(9.4 \mathrm{GHz})$ spectrometer with a standard cavity, at room temperature. The total number of spin per gram of the samples was obtained using 2.2-diphenyl-1-picrylhydrazyl as a comparison standard.

\section{Analytical measurement}

Tensile properties and Charpy impact strength were determined at least one week after processing.

Tensile tests were performed using ZWICK Z010 apparatus, according to ISO 527-1:1993. Young's modulus was measured at $1 \mathrm{~mm} / \mathrm{min}$ between 0.05 and $0.3 \%$ of strain. Five tests were performed for each series.

Yield stress, elongation and stress at break were measured at 50 or $100 \mathrm{~mm} / \mathrm{min}$, respectively for PP/HDPE1 and HDPE2/GTR blends. Eight tests were performed for each series.

For PP/HDPE1 blends, Charpy impact tests at $-22^{\circ} \mathrm{C}\left( \pm 2^{\circ} \mathrm{C}\right)$ were performed to obtain complete breaking using a Zwick 5101 pendulum with $4 \mathrm{~J}$ pendulus according to ISO 179. Notched samples ( $2 \mathrm{~mm}$ notching) were stored in a freezer during $12 \mathrm{~h}$. For other blends, impact tests were performed at ambient temperature $\left(22^{\circ} \mathrm{C}\right)$. Standard specimens were un-notched. 10 specimens were tested for each series.

Thermal properties of blends were measured by differential scanning calorimetry using DSC Setaram 
TABLE I

Mechanical Properties of Reference Blends (Standard Deviations are

Given in Brackets)

\begin{tabular}{lccc}
\hline \multicolumn{1}{c}{ Properties } & PP/HDPE1 80/20 & HDPE2 & HDPE2/GTR 50/50 \\
\hline Young's modulus $(\mathrm{MPa})$ & $381( \pm 15)$ & $958( \pm 19)$ & $457( \pm 20)$ \\
Yield stress $(\mathrm{MPa})$ & $17.5( \pm 0.2)$ & $29.0( \pm 0.2)$ & $13.9( \pm 0.4)$ \\
Elongation at break $(\%)$ & $64( \pm 10)$ & $29.2( \pm 2.8)$ & $15.9( \pm 1.3)$ \\
Impact strength $\left(\mathrm{kJ} / \mathrm{m}^{2}\right)$ & $11.5( \pm 0.7)^{\mathrm{a}}$ & $13.0( \pm 1.2)^{\mathrm{b}}$ & $3.4( \pm 0.5)^{\mathrm{b}}$ \\
\hline
\end{tabular}

${ }^{\text {a }}$ Notched specimen, test temperature: $-22^{\circ} \mathrm{C}$.

${ }^{\mathrm{b}}$ Unnotched specimen, test temperature: $22^{\circ} \mathrm{C}$.

92. Heating and cooling rate was fixed at $10 \mathrm{~K} / \mathrm{min}$. To erase thermal history of samples, a first melting step was performed. After a cooling step, crystallinity and melting temperature were measured from the second heating ramp. Crystallinity was calculated considering a melting enthalpy of $290 \mathrm{~J} / \mathrm{g}$ for a $100 \%$ crystalline polyethylene and $209 \mathrm{~J} / \mathrm{g}$ for a $100 \%$ crystalline polypropylene.

\section{In situ scanning electron microscopy observations under tensile strain}

SEM observations were performed on HDPE2/GTR blends using a Quanta 200 FEG environmental scanning electron microscope (FEI) and a microtensile test device. A more detailed description of this test is given in Sonnier et al. ${ }^{2}$ The objective was to evaluate the elongation of a GTR particle during tensile test to determine the interfacial adhesion.
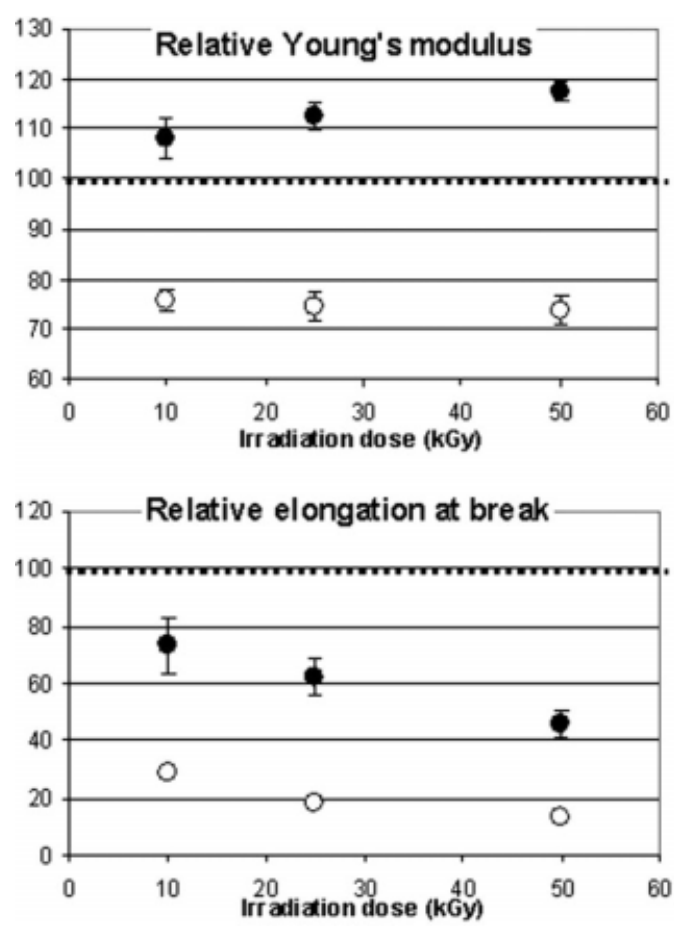

\section{RESULTS AND DISCUSSION}

To present the mechanical results in a comprehensible way; the values are given in percentage of reference value (nonirradiated PP/HDPE1 80/20, HDPE2 or HDPE2/GTR 50/50 according to the studied blend). Table I presents the absolute performances of these three blends.

\section{Irradiation of PP/HDPE1}

Mechanical properties

The first blend studied here is PP/HDPE1 80/20. Mechanical properties of irradiated molded pieces are supplied in Figure 1. A drastic decrease of elongation at break $(-50 \%$ at $50 \mathrm{kGy})$ occurs with irradiation. Impact strength and yield stress decrease slightly $(-10 \%$ in comparison with nonirradiated blend) while Young's modulus increases.
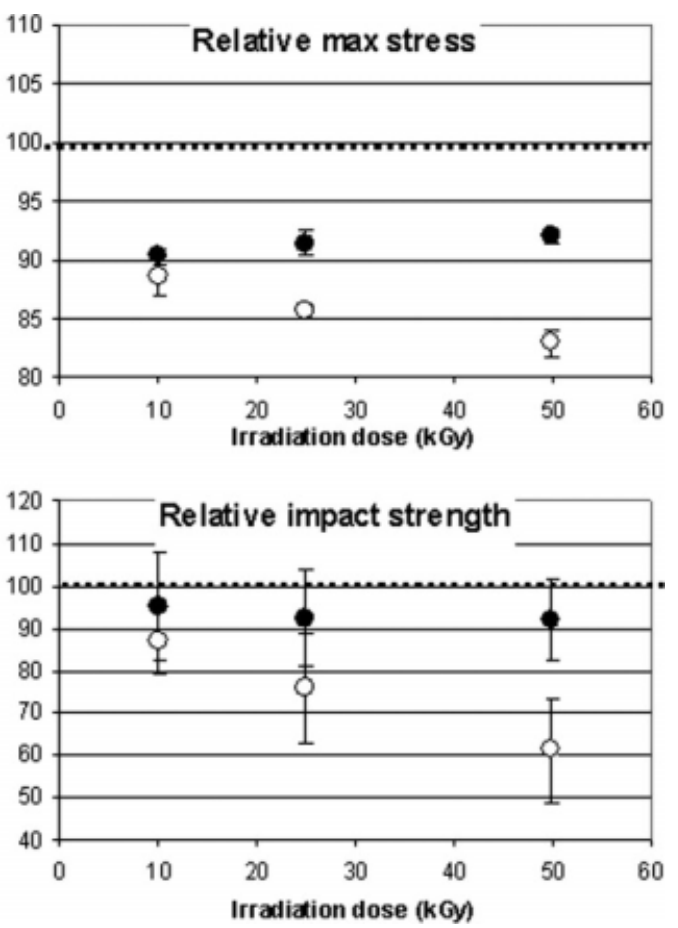

Figure 1 Mechanical properties of irradiated PP/HDPE1 80/20 compared to reference blend (values = 100 for nonirradiated blend)-Black circles correspond to irradiated molded pieces, white circles correspond to specimens obtained from irradiated pellets. 

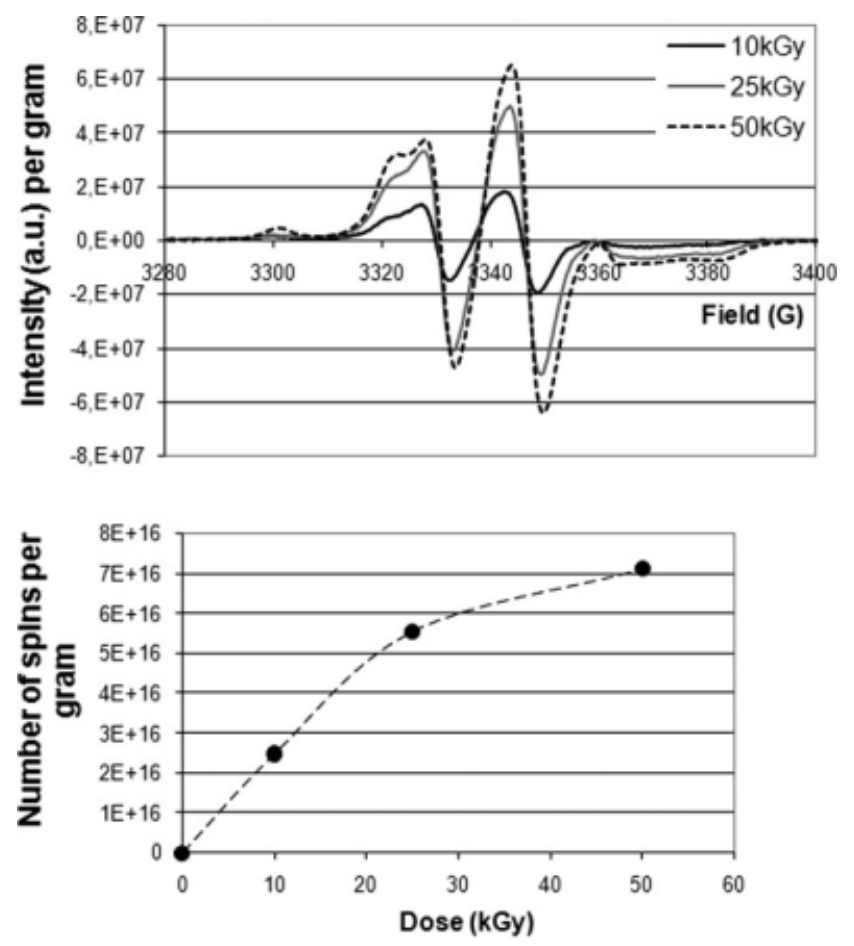

Figure 2 ESR spectra and number of spins per gram for tensile test specimen PP/HDPE1 irradiated at 10, 25, and 50 kGy after injection molding.

The degradation of PP matrix by chain scissions could explain these results. Numerous articles concerning the effect of radical reactions (by peroxides or irradiation) on PP show similar changes of the mechanical performances. ${ }^{19,20}$

The mechanical behavior of blends processed from irradiated pellets indicates the same tendencies but the loss of properties is significantly higher. This difference between both series of irradiated blends reveals the presence of trapped radicals in irradiated solid polymers. These radicals could enhance the loss of mechanical performances only if a reprocessing step gives mobility to the molecules and allows them to react. In the case of PP/HDPE1 blends, the most predominant phenomenon is the chain scission of PP. Thus, the degradation of PP matrix and the loss of properties increase.

\section{ESR results}

ESR measurements (given in Fig. 2) confirm that the trapped radicals are still present in the irradiated molded pieces in spite of the conditions of storage in air and at ambient temperature. Even 43 days after irradiation, radicals are still detected in irradiated molded pieces. Thereby, when irradiated pellets were injection-molded 13 days after irradiation, many radical reactions occurred and enhanced the degradation of PP.
ESR spectra of PP/HDPE1 blends indicate the presence of different radicals. For PE alone, Assink et al. ${ }^{18}$ have identified alkyl, allyl, polyenyl radicals. Peroxy radicals have been also present in a low content. According to eqs. (1), alkyl and peroxy radicals could be observed for PP. ${ }^{16,17}$ Nevertheless the assignement of peaks to different radical types remain rather difficult.

The concentration of radicals $\left(\sim 10^{16}\right.$ spins $\left./ \mathrm{g}\right)$ is in agreement with other studies. Perera et al. ${ }^{21}$ measure $3.10^{17} \mathrm{spins} / \mathrm{g}$ for PP irradiated at $50 \mathrm{kGy}$. After $500 \mathrm{~h}$ (more than 20 days), the concentration decreases below $10^{17}$ spins/g. After 1 month, Assink et al. ${ }^{18}$ determine a concentration of $10^{16}$ polyenyl radicals per gram of PE. On the contrary, Chen et al. ${ }^{16}$ notice that radicals disappear completely after 20 days at ambient temperature, but irradiation


Figure 3 Thermal analysis of irradiated PP/HDPE1 $80 / 20$. 

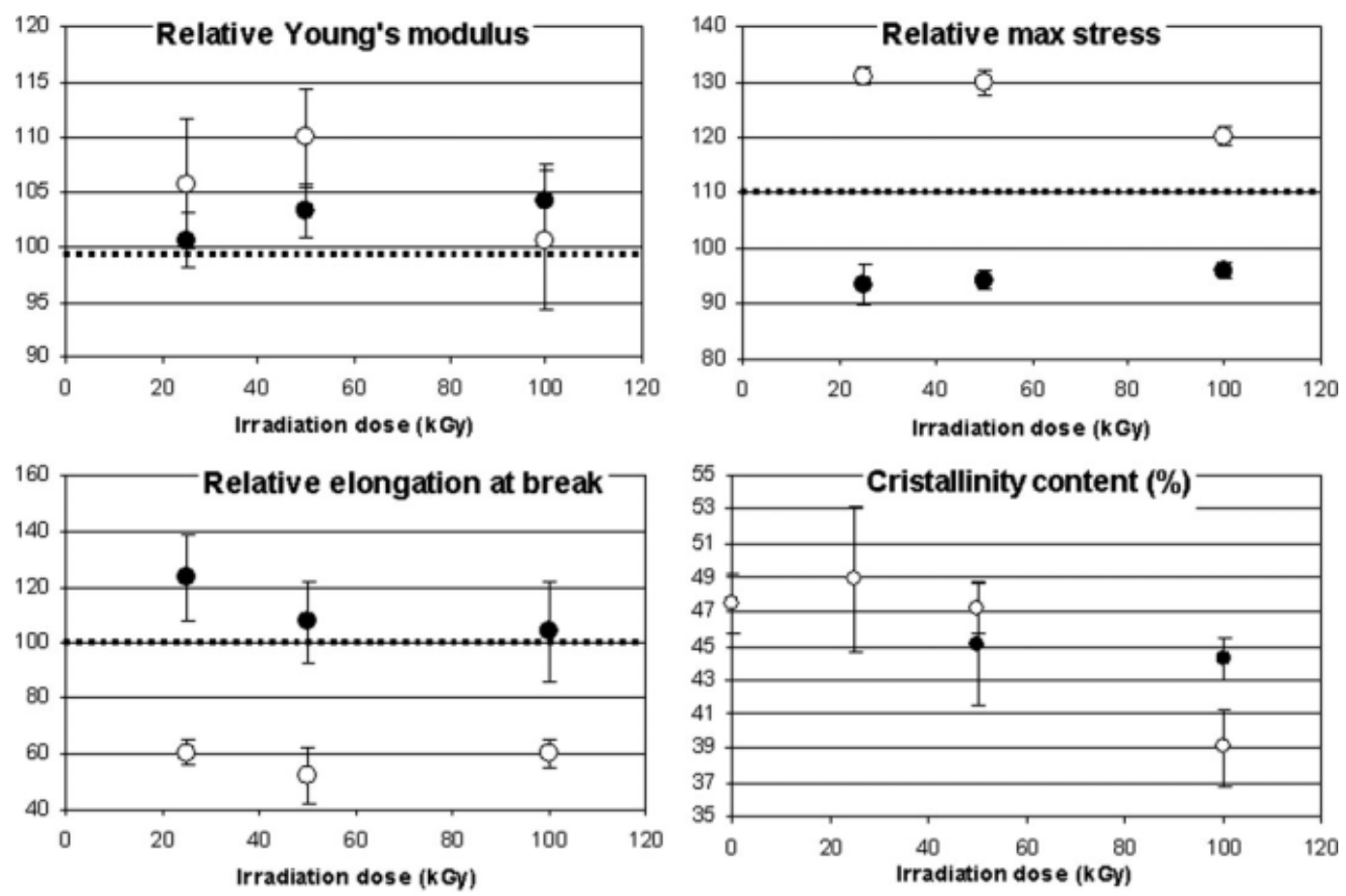

Figure 4 Mechanical properties of irradiated HDPE2 compared to reference HDPE2 (values = 100 for nonirradiated HDPE2) and crystallinity content of irradiated HDPE2-Black circles correspond to irradiated molded pieces, white circles correspond to specimens obtained from irradiated pellets.

was performed on films and diffusion of oxygen was probably faster.

The last remark concerns the influence of irradiation doses on the concentration of radicals. The increase of spin concentration is approximately linear between 0 and $25 \mathrm{kGy}$ and lower beyond $25 \mathrm{kGy}$. Perera et al. ${ }^{21}$ have noticed the same behavior. A high concentration of radicals favors their recombination and explains the curve shape.

\section{Thermal properties}

Crystallinity index of PP and HDPE1 does not show significant changes for any of the blends as illustrated in Figure 3. We assume that the irradiation doses were too low to change the crystallinity, in particular for HDPE1. Perera et al. ${ }^{21}$ have not observed any change in PP crystallinity up to $100 \mathrm{kGy}$. In the following section of the present article, it is shown that the crosslinking reduces the crystallinity index of HDPE2 only for a dose higher than $50 \mathrm{kGy}$. The melting temperature of HDPE1 was also stable.

But the melting temperature of PP shifts from $167.1^{\circ} \mathrm{C}$ to $163^{\circ} \mathrm{C}$ for $50 \mathrm{kGy}$. A shoulder on the melting peak could be observed at lower temperatures and points out the presence of several populations of crystals which have different lamellar thickness. The shift of melting temperature is due to unperfect crystals and is in agreement with the scission of PP chains due to irradiation. ${ }^{4,21}$

For a given dose, we could not notice any difference between irradiated molded pieces and specimens molded from irradiated pellets in spite of the reprocessing which releases radicals trapped in crystallites and enhances the degradation of PP. To explain this observation which is not in agreement with mechanical tests, we assume that a heating ramp during DSC analysis releases trapped radicals in irradiated molded pieces. These radicals could provoke additional chain scissions and PP degradation.

The last observation concerns the efficiency of the irradiation in the compatibilization process of the PP/HDPE blends. Radicals created by irradiation contributed to the degradation of PP. In the case of blends based on PP matrix, this treatment could not improve mechanical properties, even if some covalent bondings may be created at the interface. Another treatment must be suggested. For example, using polyfunctional monomer to enhance crosslinking of PP by irradiation is a possible way. 3,14

\section{Irradiation of HDPE2}

Irradiation before injection molding (pellets)

HDPE2 specimen obtained from irradiated pellets show significant variations of properties (Fig. 4). Young's modulus and yield stress increase while 



Figure 5 Mechanical properties of HDPE2/GTR (100\% for nonirradiated blend)—Black circles correspond to irradiation after injection molding, white circles correspond to irradiation before injection molding.

elongation at break decreases up to 25-50 kGy. Above theses doses, new tendencies could be observed: Young's modulus and yield stress decrease and elongation at break is stable. Impact strength (not shown here) follows the same tendency as elongation at break.

These changes are in agreement with the literature concerning the crosslinking of HDPE by peroxide or irradiation. Branching and crosslinking lead to higher stiffness. When the level of crosslinking is too high, crystallinity is reduced and stiffness decreases. On the contrary, properties related to ductility stabilize.

Crystallinity measurements (shown in Fig. 4) confirm these explanations. Up to $50 \mathrm{kGy}$, crystallinity content does not change, indicating that crosslinking is not enhanced enough to disturb the crystallization. On the contrary, above $50 \mathrm{kGy}$, the crystallinity content decreases. We could note that crystallinity and Young's modulus are closely related. The formation of crosslinks disrupts the crystallization. So, crystallinity is reduced from $48 \%$ to $39 \%$ and crystallites are smaller (leading to lower melting temperature, not shown here). Similar results are obtained for the electron beam or gamma irradiation of PE. $1,8,10,22-24$

Irradiation after injection molding (molded parts)

Contrary to above results, mechanical properties and crystallinity content of irradiated molded pieces hardly change, even at 100 kGy (as shown in Fig. 4).
Except for maximum stress, all variations are lower than standard deviations. It is so assumed that no crosslinks (or very few crosslinks) are created during irradiation. This result contrasts significantly with the irradiation of PP (Fig. 3).

Two hypothesis could be proposed to explain this observation. HDPE is more crystalline than PP and so more radicals are trapped in HDPE2 and could not react if irradiation is not followed by a melting step. But crystallinity of HDPE2 is only 50\% against $40 \%$ for PP.

The second hypothesis concerns the type of reactions involved in PP and HDPE. In the first polymer, chain scissions are directly caused by the rearrangement of a macroradical which leads to a double bonding and a new macroradical. So, it is an intramolecular reaction. In the case of HDPE, crosslinking needs the combination of two macroradicals. It is an intermolecular reaction and the mobility of these macroradicals is a critical parameter: Without heating, few reactions could take place.

\section{Irradiation of HDPE2/GTR}

Concerning the HDPE2/GTR 50/50 blends, irradiation of molded pieces confirms the results obtained with HDPE2. No significant changes in mechanical properties could be noticed (Fig. 5). Crosslinking of HDPE2 or co-crosslinking (it means creation of covalent bondings between macroradicals of the two polymers at the interface) do not occur because the low 

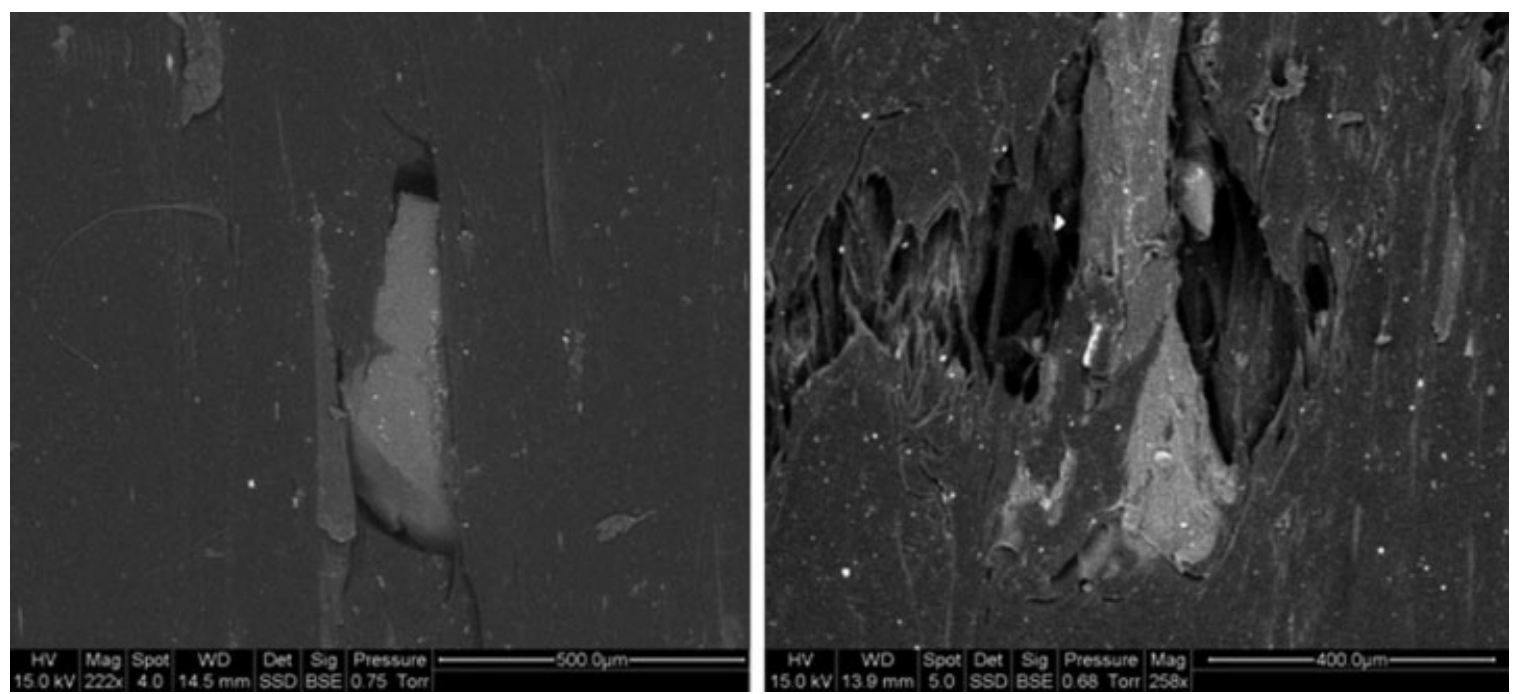

Figure 6 In situ SEM observations during tensile test on HDPE2/GTR blends-right: nonirradiated HDPE2/GTR—left: HDPE2/GTR irradiated and then injection molded.

mobility of macroradicals at ambient temperature does not allow the intermolecular reactions like recombination.

On the contrary, irradiation of the pellets before the melting step leads to drastic change in mechanical performances. Moreover, these changes are opposite to the tendencies observed in the case of HDPE2 alone (Fig. 4). Young's modulus decreases while elongation at break, impact strength and yield stress increases for doses higher than 15-25 kGy. But above $50 \mathrm{kGy}$, these properties stabilize or decrease, e.g., elongation at break.

Crosslinking of HDPE2 is induced by irradiation. But these changes prove that an additional phenomenon occurs during irradiation of HDPE2/GTR blends: interfacial co-crosslinking improves the adhesion between both phases. So the elongation at break which is the property the most dependent on the compatibility between polymers increases. An efficient compatibilization could be performed with irradiation, in the case of crosslinkable polymers.

In situ SEM observations during tensile test confirm these results (Fig. 6). For nonirradiated HDPE2/GTR blend, the debonding between the HDPE2 matrix and the GTR particle happens instantaneously and the particle is not elongated. When irradiation was performed before injection molding, the GTR particle could undergo a strong elongation before debonding. More detailed results are given in Sonnier et al. ${ }^{2}$

\section{CONCLUSIONS}

Different polymers or blends (HDPE, PP/HDPE and HDPE/GTR) were irradiated by a ${ }^{60} \mathrm{Co}$ source, before and after injection-molding. Upon the obtained results the following conclusions were drawn:

1. Numerous radicals created by irradiation remain in materials during a long time, even when the irradiated molded pieces are stored at ambient temperature and in air. These trapped radicals could react and enhance the structure degradation of polymers if a new processing step is performed. So, irradiation before and after injection-molding leads to two different materials in the point of view of the structure and mechanical behavior.

2. The rearrangement of a macroradical which involves a chain scission is an intramolecular reaction. The crosslinking by combination of two macroradicals is an intermolecular reaction which depends on radical mobility. So if no processing step is performed after irradiation, the extent of this second phenomenon may be very limited.

3. Due to the chain scissions of PP, irradiation is not an efficient way to compatibilize a blend containing PP as matrix. On the contrary, for a blend between two polymers which undergo preferentially crosslinking, an irradiation step followed by injection-molding appears as an efficient compatibilizing treatment.

4. When irradiation is performed on pellets and is followed by injection-molding, all free radicals could react: the effect of irradiation is enhanced and lower doses are sufficient. The process is more cost-efficient.

The authors thank Dr. Sophie Rouif from Ionisos SA and to Dr. Claire Longuet for their help. 


\section{References}

1. Maziad, N. A.; Hassan, M. M. J Appl Polym Sci 2007, 106, 4157.

2. Sonnier, R.; Leroy, E.; Bergeret, A.; Lopez-Cuesta, J. M. Polym Degrad Stab 2006, 91, 2375.

3. Ali, Z. I.; Youssef, H. A.; Said, H. M.; Saleh, H. H. Adv Polym Technol 2006, 25, 208.

4. Adem, E.; Burillo, G.; Avalos-Borja, M.; Carreon, M. P. Nucl Instrum Methods Phys Res B 2005, 236, 295.

5. Martinez-Barrera, G.; Lopez, H.; Castano, V. M.; Rodriguez, R. Radiat Phys Chem 2004, 69, 155.

6. Albano, C.; Reyes, J.; Ichazo, M.; Gonzalez, J.; Hernandez, M.; Rodriguez, M. Polym Degrad Stab 2003, 80, 251.

7. Dalai, S.; Wenxiu, C. J Appl Polym Sci 2002, 86, 553.

8. Khonakdar, H. A.; Jafari, S. H.; Wagenknecht, U.; Jehnichen, D. Radiat Phys Chem 2006, 75, 78.

9. Gheysari, D.; Behjat, A. Eur Polym J 2001, 37, 2011.

10. Miguez Suarez, J. C.; Da Costa Monteiro, E. E.; Mano, E. B. Polym Degrad Stab 2002, 75, 143.

11. Dluzneski, P. In Proceedings of the International Rubber Conference; Lyon, France, 2006.

12. Dalai, S.; Wenxiu, C. J Appl Polym Sci 2002, 86, 3420.
13. Lugao, A. B.; Hutzler, B.; Ojeda, T.; Tokumoto, S.; Siemens, R.; Makuuchi, K.; Villavicencio, A. L. Radiat Phys Chem 2000, 57, 389.

14. Han, D. H.; Shin, S. H.; Petrov, S. Radiat Phys Chem 2004, 69, 239.

15. Shukushima, S.; Hayami, H.; Ito, T.; Nishimoto, S. Radiat Phys Chem 2001, 60, 489.

16. Chen, J.; Yang, L.; Chen, L.; Wu, M.; Nho, Y. C.; Kaetsua, I. Radiat Phys Chem 2004, 69, 149.

17. Rivaton, A.; Lalande, D.; Gardette, J.-L. Nucl Instrum Methods Phys Res B 2004, 222, 187.

18. Assink, R. A.; Celina, M.; Dunbar, T. D.; Alam, T. M.; Clough, R. L.; Gillen, K. T. Macromolecules 2000, 33, 4023.

19. Machado, A. V.; Covas, J. A.; Van Duin, M. J Appl Polym Sci 2001, 81, 58

20. Azizi, H.; Ghasemi, I. Polym Test 2004, 23, 137.

21. Perera, R.; Albano, C.; Gonzalez, J.; Silva, P.; Ichazo, M. Polym Degrad Stab 2004, 85, 741.

22. Miguez Suarez, J. C.; Mano, E. B.; Pereira, R. A. Polym Degrad Stab 2000, 69, 217.

23. Gheysari, D.; Behjat, A.; Haji-Saeid, M. Eur Polym J 2001, 37, 295.

24. Hutzler, B. W.; Machado, L. D. B.; Villavicencio, A. L. C. H.; Lugao, A. B. Radiat Phys Chem 2000, 57, 431. 